\title{
Oblique Flashlight Test: Lighting Up Acute Angle-Closure Glaucoma
}

\author{
Kiyoshi Shikino, MD, PhD, Yuta Hirose, MD, and Masatomi Ikusaka, MD, PhD \\ Department of General Medicine, Chiba University Hospital, Chiba-city, Chiba Prefecture, Japan.
}

KEY WORDS: acute angle-closure glaucoma; oblique flashlight test.

J Gen Intern Med 31(12): 1538

DOI: $10.1007 / \mathrm{s} 11606-016-3737-8$

(c) Society of General Internal Medicine 2016

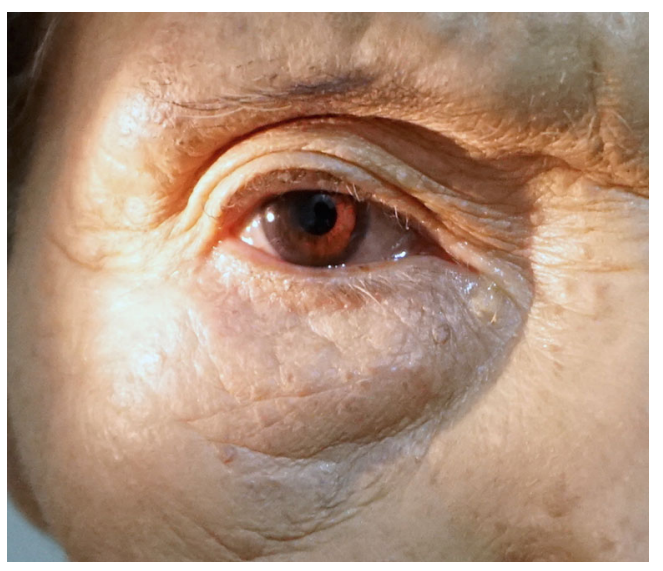

Figure 2 Showing a normal eye without shadowing.

Corresponding Author: Kiyoshi Shikino, MD, PhD; Department of General MedicineChiba University Hospital, 1-8-1, Inohana, Chuo-ku, Chiba-city, Chiba Prefecture, Japan (e-mail: kshikino@gmail.com).

\section{Compliance with Ethical Standards:}

Conflict of Interest Statement: The authors declare that they do not have a conflict of interest.

\section{REFERENCES}

1. He M, Huang W, Friedman DS, Wu C, Zheng Y, Foster PJ. Slit lampsimulated oblique flashlight test in the detection of narrow angles in Chinese eyes: the Liwan eye study. Invest Ophthalmol Vis Sci. 2007;48(12):5459-63.

Figure 1 Oblique flashlight test showing a shadow projecting onto the nasal iris (arrow).

Received March 28, 2016

Revised April 27, 2016

Accepted May 2, 2016

Published online May 12, 2016 